CONOCIMIENTO, REPRESENTACIONES Y COMPORTAMIENTOS SOCIALES EN TORNO A LA “MASACRE DE TRELEW" EN BAHÍA BLANCA Y PUNTA ALTA (AGOSTO-NOVIEMBRE 1972)

\author{
VIRGINIA DOMINELLA (UNS - CONICET) \\ Departamento de Humanidades, Universidad Nacional del Sur, Bahía Blanca \\ v dominella@yahoo.com.ar
}

\begin{abstract}
Resumen:
Si bien la "Masacre de Trelew" sacudió a todo el país, Bahía Blanca y Punta Alta se vieron movilizadas en forma particular por diversas razones. Una de ellas fue la cercanía de los sobrevivientes y sus familiares. Este artículo aborda la elaboración de conocimiento, la circulación de información y la conformación de representaciones sobre el acontecimiento de Trelew en dichas ciudades en las horas, los días y las semanas posteriores a los hechos. Asimismo, analiza las actitudes y los comportamientos asumidos frente a ellos por diversos actores locales. ¿Qué informaciones circularon sobre la "Masacre" y cómo? ¿Qué pudo conocerse de aquélla? ¿Qué rol ocupó la prensa local y los familiares de los sobrevivientes? ¿Qué sentidos se construyeron sobre el acontecimiento? ¿Cómo reaccionaron los abogados defensores de presos políticos, los sectores estudiantiles, los católicos liberacionistas y los colectivos artísticos militantes?
\end{abstract}

Palabras claves:

Representaciones - Comportamientos Sociales - Masacre de Trelew - Bahía Blanca - Punta Alta

\begin{abstract}
:
Even though the "Trelew massacre" agitated the entire country, the cities of Bahía Blanca and Punta Alta were particularly affected for several reasons. One of them was the proximity of the survivors and their families. This article addresses the elaboration of knowledge, the information flow and the conformation of representations about Trelew's event in these cities in the following hours, days and weeks. Additionally, it analyses the attitudes and behaviours adopted towards them for several local actors. What kind of information circulated about the "massacre" and how it spread? What could be known about such event? What was the role of the local press and the role of the survivors' families? What was said about the killings? How did the political prisoners' defence lawyers, the student sectors, the liberationists Catholics and the activist artistic collectives reacted?
\end{abstract}

Key words:

Representations - Social Behavior - Trelew Massacre - Bahía Blanca - Punta Alta 


\title{
CONOCIMIENTO, REPRESENTACIONES Y COMPORTAMIENTOS SOCIALES EN TORNO A LA "MASACRE DE TRELEW" EN BAHÍA BLANCA Y PUNTA ALTA (AGOSTO-NOVIEMBRE 1972)
}

\author{
VIRGINIA DOMINELLA (UNS - CONICET)
}

vdominella@yahoo.com.ar

\section{Introducción}

Este artículo aborda la elaboración de conocimiento, la circulación de información y la conformación de representaciones sobre la "Masacre de Trelew" en Bahía Blanca y Punta Alta en las horas, los días y las semanas posteriores a los hechos. Asimismo, analiza las actitudes y los comportamientos asumidos por diversos actores locales en respuesta a esos sucesos ${ }^{1}$. En este sentido, busca reflexionar en torno a los siguientes interrogantes: ¿Qué informaciones circularon sobre la "Masacre" en el ámbito bahiense y puntaltense? ¿Cómo y por qué canales lo hicieron? ¿Qué pudo conocerse de los sucesos del 22 de agosto de 1972? ¿Qué rol ocupó la prensa local y los familiares de los sobrevivientes en ese proceso? ¿Qué sentidos se construyeron sobre aquellos hechos? ¿Cómo reaccionaron los abogados defensores de presos políticos, los sectores estudiantiles, los católicos liberacionistas y los colectivos artísticos militantes frente a la "irrupción de la Masacre" en el espacio local con la llegada de los heridos y sus familias? ¿Cómo se movilizaron y con qué objetivos? Para ello, se utilizan fuentes periodísticas, informes de la Dirección de Inteligencia de la Policía de la Provincia de Buenos Aires (DIPPBA), publicaciones católicas oficiales, volantes y testimonios orales.

El 22 de agosto de 1972 en la Base Aeronaval “Almirante Zar” de Trelew, fueron asesinados 16 presos políticos y militantes de Montoneros, Fuerzas Armadas Revolucionarias y Partido Revolucionario de los Trabajadores-Ejército Revolucionario del Pueblo que siete días antes habían protagonizado un intento de fuga del penal de Rawson. Al mismo tiempo, fueron heridos de gravedad Alberto Camps, María Antonia Berger y Ricardo René Haidar, quienes fueron trasladados al hospital de la Base Naval de "Puerto Belgrano" de Punta Alta durante las horas siguientes $^{2}$. Al mismo tiempo, arribaron a Bahía Blanca no sólo los padres, hermanos y

\footnotetext{
1 Este trabajo se inscribe en mi investigación doctoral Dominella, Virginia, Catolicismo liberacionista y militancias contestatarias en Babia Blanca: sociabilidades y trayectorias en las ramas especializadas de Acción Católica durante la efervescencia social y politica de los años '60 y '70, Tesis de Doctorado en Historia, Universidad Nacional de La Plata, La Plata, 2015, en línea en: http://www.memoria.fahce.unlp.edu.ar/tesis/te.1180/te.1180.pdf., consulta: 28/4/2017. Surgió del interés por reconstruir las relaciones de los católicos liberacionistas locales con el acontecimiento de Trelew. De allí que si bien incluye a otros actores cuya importancia emergió de las fuentes recabadas, conserva una mirada que le otorga gran protagonismo a un grupo de sacerdotes y laicos. Por otra parte, el artículo se enmarca en el PICT Bicentenario2010-1538, ANPCyT-FONCyT La elaboración de conocimiento, la circulación de ideas y la constitución de representaciones sobre las desapariciones en la Argentina (1975 -1983) (investigador responsable: Emilio Crenzel). Una versión preliminar fue presentada en las VII Jornadas de Trabajo sobre Historia Reciente (Ensenada, agosto de 2014). Agradezco los comentarios que a distintas versiones de este trabajo han hecho Silvina Jensen, Julia Giménez y Laura Lenci, enriqueciendo mi perspectiva.

2 Telegrama del comisario Trujillo e "Informe sobre extremistas heridos internados hospital Base Naval Puerto Belgrano" del 25/8/72, Mesa "D(s)", Carpeta Varios, Legajo 383, Tomo 1. FONDO DIPPBA División Central de Documentación, Registro y Archivo. La Nueva Provincia (LNP), Bahía Blanca, 23/8/72, "Dos heridos fueron
} 
compañeros de los heridos sino también de los asesinados como fue el caso de Alicia Leichuk, la esposa de Rubén Bonet ${ }^{3}$. Inmediatamente, los familiares tomaron contacto con abogados locales defensores de presos políticos ${ }^{4}$, entre los que se encontraban Everardo Facchini y Víctor Benamo ${ }^{5}$. Sin embargo, no pudieron ver a los militantes hasta el 28 de agosto, cuando las autoridades navales levantaron la incomunicación previamente impuesta.

Si bien los fusilamientos de Trelew sacudieron a todo el país, Bahía Blanca y Punta Alta se vieron movilizadas en forma particular por diversas razones. En primer lugar, por la cercanía de los sobrevivientes y familiares durante los días siguientes. Además, las ciudades concentraron a abogados de presos políticos provenientes de Buenos Aires, Santa Fe, Córdoba y Entre Ríos que fueron recibidos por los defensistas locales 6 . Para Mario Landabaru, Héctor Sandler, Rafael Lombardi y Adalberto Cavilla, pertenecientes a la Asociación Gremial de Abogados de la Capital $\mathrm{Federal}^{7}$, que el 23 viajaron a Rawson para interiorizarse de la situación de sus defendidos y volvieron al día siguiente, Bahía Blanca era también un lugar de paso ${ }^{8}$. En ello influía la estratégica posición geográfica de la ciudad como nudo de comunicaciones y puente que vincula Buenos Aires con la Patagonia.

En segundo lugar, estas ciudades eran, desde fines del siglo XIX, asiento de diversas guarniciones militares y de organismos de defensa y de seguridad, lo que daba cuenta de su importancia desde el punto de vista militar. Estas unidades, para mediados de la década de 1970, incluían: la Base Naval "Puerto Belgrano"; la Base Aeronaval "Comandante Espora"; la Base Naval de Infantería de Marina; el Comando del V Cuerpo del Ejército que, erigido en 1960, extendía su jurisdicción a toda la Patagonia; la Compañía de Intendencia 181, el Batallón de Comunicaciones 181, la Policía Militar y el Destacamento de Inteligencia Militar 181, que establecidas a lo largo de la década de

trasladados a la Base Pto. Belgrano"; LNP, Bahía Blanca, 24/8/72, "Los sobrevivientes están internados en la Base de Puerto Belgrano".

${ }^{3}$ LNP, Bahía Blanca, 23/8/72, "Pasó por Bahía Blanca en viaje a Trelew un grupo de abogados".

${ }^{4} \mathrm{La}$ existencia de abogados bahienses defensores de presos políticos, así como sus contactos con defensistas de otros puntos del país está referenciada en las fuentes. Se menciona, por ejemplo, a la Asociación de Abogados contra la Legislación Represiva de Bahía Blanca y la Liga de Defensa de los Derechos del Hombre (sic) (LNP, Bahía Blanca, 23/8/72). Sin embargo, no se cuenta con todos los nombres de los abogados locales que actuaron en agosto de 1972 -no aparecen mencionados en la prensa o fueron tachados en los informes de la DIPPBA debido a las políticas de protección de la información de la Comisión Provincial por la Memoria- ni con mayor información sobre el funcionamiento de estas agrupaciones en el ámbito bahiense -más allá de que se conoce que la Liga Argentina por los Derechos del Hombre tuvo actividad ininterrumpida en el país desde 1937 y estaba vinculada al Partido Comunista (Véase Eidelman, Ariel, "El PRT-ERP y la lucha por la libertad de los presos políticos, 1971-1973”, Sociobistórica, 25, La Plata, primer semestre de 2009, págs. 13-39). Por otra parte, no hay estudios centrados en el abordaje de los abogados de presos políticos en esta región. ¿Quiénes eran? ¿Qué era aquella Asociación? ¿Qué vínculos mantenían con la Asociación Gremial de Abogados de la Capital Federal? ¿Qué redes y contactos previos, si los hubo, facilitaron a abogados defensistas de Córdoba o Santa Fe recalar en Bahía Blanca en agosto de 1972? Son interrogantes que permanecen abiertos.

${ }^{5}$ La participación de Facchini en los sucesos que aquí analizamos aparece mencionada en la entrevista a Hugo Segovia, Mar del Plata, 27/5/2010, y en la realizada por Belén Zapata a Víctor Benamo en Bahía Blanca, el 19/8/2008. Aquí, Benamo también se refirió a su contacto con los familiares y sobrevivientes. Ambos eran referentes de la izquierda peronista en Bahía Blanca, y trabajaron juntos en la defensa de presos políticos y de distintos sindicatos. Véase Zapata, Belén, Andamios de experiencias: Conflictividad obrera, vigilancia y represión en Argentina. Babia Blanca, 1966-1976, Tesis de Doctorado en Historia, Universidad Nacional de La Plata, La Plata, 2014.

"LNP, Bahía Blanca, 25/8/72, "Telegrama". Telegrama s/f elevado a la DIPPBA e "Informe sobre extremistas heridos..." del 25/8/72, “Ampliar Memorando Dpto. "D” 104", del 29/8/72, Mesa "D(s)", Carpeta Varios, Legajo 383, Tomo 1. Fondo DIPPBA.

${ }^{7}$ Creada a mediados de 1971 y orientada a la defensa de presos políticos, incluía a profesionales que cubrían un amplio espectro ideológico-político pero compartían la oposición al régimen militar y el cuestionamiento al "sistema social” en su conjunto. Véase Chama, Mauricio, "Movilización y politización: abogados de Buenos Aires entre 1968 y 1973", en Perotin-Dumon, Anne, (dir.), Historizar el pasado vivo en América Latina, 2007, págs. 1-26, en línea en: http://www.historizarelpasadovivo.cl//, consulta: 01/09/2015.

${ }^{8}$ LNP, Bahía Blanca, 23/8/72, "Pasó por Bahía Blanca...”. LNP, Bahía Blanca, 24/8/72, "Regreso de Sandler". 
1960 y principios de 1970, estaban subordinadas a este Comando; la Delegación Sur de Gendarmería Nacional; la Prefectura Naval Argentina; la Delegación de la Secretaría de Inteligencia del Estado; la Delegación de la Policía Federal Argentina; la Brigada de Investigaciones y la Unidad Regional Quinta de la Policía de la Provincia de Buenos Aires.

Por otra parte, Bahía Blanca albergaba, desde mediados de la década de 1950, la sede de la Universidad Nacional del Sur (UNS), así como de la Universidad Tecnológica Nacional y de una serie de institutos terciarios -como el salesiano "Juan XXIII" o la Escuela de Servicio Social-, cuyos estudiantes protagonizaban por entonces una creciente movilización que había comenzado en 1969 y tuvo una escalada inédita desde mediados de 1971, a partir del recrudecimiento de la persecución de militantes políticos. Un hito en este proceso lo constituyó la detención del estudiante de Ingeniería de la UNS y militante de la Agrupación Universitaria de Acción Liberadora -ligada al Partido Comunista Revolucionario (PCR)-, Guillermo López Chamadoira, en agosto de 1971, y su condena a dos años de prisión por habérsele encontrado en su casa "material subversivo". Esto conmocionó al movimiento estudiantil y acercó a las agrupaciones en una lucha abierta contra el gobierno y por la libertad de los presos políticos?.

Asimismo, la ciudad se encontraba movilizada en la defensa de los presos políticos a partir de diversas iniciativas contra las medidas represivas de la dictadura militar, que se sucedían desde 1969, e incluían a diversos sectores no sólo estudiantiles, sino también gremiales ${ }^{10}$ y del catolicismo liberacionista. Los últimos conformaban una red de espacios sociales integrados por sacerdotes (entre ellos, los diocesanos José Zamorano, Emilio Flores, Hugo Segovia, Miguel Sarmiento, Néstor Navarro, y los salesianos Benjamín Stocchetti, Benito Santecchia, Duilio Biancucci y Oscar Barreto), religiosas y laicos (como la Juventud Universitaria Católica -JUC-, la Juventud Obrera Católica -JOC-, la Juventud Estudiantil Católica -JEC-, el Grupo Misionero Bahiense -GMB-, entre otros) identificados con el Concilio Vaticano II (1962-1965) y la Conferencia Episcopal de Medellín (1968) ${ }^{11}$. Así, la significación que los hechos de Trelew adquirieron en el ámbito local tiene como trasfondo estos antecedentes. La preocupación que la "Masacre" despertó en el movimiento estudiantil, los defensistas o los sacerdotes renovadores bahienses, y las acciones que emprendieron en consecuencia se comprenden en el marco de su

\footnotetext{
9 Véase Orbe, Patricia, La politica y lo politico en torno a la comunidad universitaria babiense (1955-1976). Estudio de grupos, ideologias y producción de discursos, Tesis de Doctorado en Historia, Universidad Nacional del Sur, Bahía Blanca, 2007; Giménez, Julia, Ciudad de "Perros". Historias de militancia y recorridos del PRT-ERP por la ciudad de Babia Blanca., Tesis de Licenciatura en Historia, Universidad Nacional del Sur, Bahía Blanca, 2008; Romero Wimer, Fernando y Becher, Pablo, "Los estudiantes y las luchas de calles en Bahía Blanca durante 1972", Conflicto Social, año 4, n 5, Buenos Aires, 2011, en línea en: http://webiigg.sociales.uba.ar/conflictosocial/revista/05/12 wimwer-becher.pdf., consulta: 14/07/15; Bonavena, Pablo, "Notas sobre el movimiento estudiantil de Bahía Blanca (1966-1973)", en Bonavena, Pablo et. al., Apuntes sobre la formación del movimiento estudiantil argentino (1943-1973), Buenos Aires, Final Abierto, 2010, págs. 225-254.

10 Véase Zapata, Belén, Andamios de experiencias..., op. cit.

${ }^{11}$ Segovia era secretario canciller de la Curia (1967-1974) y coordinaba la Juventud de Acción Católica de Punta Alta. Sarmiento acompañaba el GMB, era director arquidiocesano de Catequesis y, desde 1972, párroco de Cristo Rey, en Punta Alta. Zamorano y Flores eran misioneros españoles llegados a la ciudad en 1967, estaban a cargo de la iglesia "Nuestra Señora del Carmen", atendían el centro pastoral "La Pequeña Obra", donde acompañaron un movimiento Scout-Guía, y eran asesores de la JUC. Emilio, que era docente de la Escuela de Servicio Social, abandonó la ciudad en 1971. José asesoró también la JOC y la JEC hasta 1975. Navarro era el director de Cáritas Arquidiocesana. Los salesianos formaban parte de la comunidad del Instituto "Juan XXIII", donde se desempeñaban como profesores, ocupando algunos de ellos el cargo de rector (Santecchia, en 1973, y Stocchetti en 1974-1975). Santecchia era un teólogo reconocido más allá del ámbito católico. Biancucci era además profesor de la UNS (1971-1973). Véase Dominella, Virginia, "Espacios de sociabilidad, redes sociales de la renovación católica y militancia contestataria en Bahía Blanca (Argentina), entre 1968 y 1975”, Revista Cultura y Religión, vol. IX, nro. 1, Universidad Arturo Prat del Estado de Chile, Iquique, enero-junio de 2015, págs. 102-128, en línea en: www.revistaculturayreligion.cl/index.php/culturayreligion/article/download/593., consulta: 15/01/2017.
} 
involucramiento previo en la defensa de los militantes políticos locales perseguidos, encarcelados sin haber sido sometidos a proceso, y torturados ${ }^{12}$.

Por último, debe mencionarse que Bahía Blanca y Punta Alta se hallan conectadas por la proximidad geográfica $-20 \mathrm{~km}$. de distancia-, el movimiento diario de muchos de sus habitantes por cuestiones laborales o de estudio, y la común pertenencia a la Arquidiócesis de Bahía Blanca de allí que algunos de los sacerdotes mencionados desarrollaran tareas pastorales en ambas localidades. Con todo, se trata de ciudades de dimensiones medianas que delimitan un entretejido de redes sociales relativamente estrecho, que facilitó la circulación de información sobre los sucesos ocurridos en la Base "Almirante Zar" y la elaboración de acciones colectivas.

\section{Lo que se decía, lo que se ocultaba, lo que se sabía}

Siguiendo a Pittaluga, si bien no era la primera vez que las fuerzas armadas o policiales de nuestro país procedían al fusilamiento masivo de detenidos políticos, por lo que la "Masacre de Trelew" puede ser legítimamente leída a partir de los crímenes que la preceden, también es cierto que tuvo un conjunto peculiar de atributos que la vinculan con las formas de represión de la disidencia política y de disciplinamiento social que se instalaron en los años siguientes. Si otras masacres permanecieron ocultas durante largos años y sus perpetradores las quisieron absolutamente invisibles, la de 1972 tuvo un carácter público e inocultable: el escenario del crimen era una instalación del Estado, donde era de público conocimiento que estaban alojados los 19 militantes. Además, el gobierno militar no negó su existencia, aunque no habló claramente. Así, se trataba de instalar la masacre en una región a medias visible e invisible, dejando que lo no dicho actuara a su manera. Lo que se decía oficialmente mostraba el ocultamiento, para señalar que ese crimen estaba situado más allá de lo que podía decirse. Se buscaba exponer ante la sociedad ese sitio y ese poder más allá de la ley. De este modo, el crimen de Trelew prefiguraba la doble dimensión del exterminio planificado tal como se produjo en Argentina: la superposición de las funciones públicas formalmente admitidas para ciertos espacios y sus destinos cuasi-secretos en la producción y gestión del exterminio; y la imposibilidad de nombrar lo que se sabe que sucede, o decirlo de modo distorsionado. Estas similitudes hablan del paulatino despliegue del terrorismo de Estado, entendiendo por éste no sólo el terror que el Estado aplicó, sino también la constitución de determinadas relaciones sociales y subjetividades que han internalizado esa condición ${ }^{13}$.

Una pieza adicional de la decisión del fusilamiento fue la férrea censura de la información periodística, implementada a través de una serie de "decretos leyes" emitidos por el gobierno militar el 22 de agosto $^{14}$. Así, éste construyó un relato sobre lo ocurrido y, ante la incapacidad de sostenerlo con argumentos lógicos, recurrió a la coacción para impedir toda averiguación que diera lugar a otra narración. En este marco, los medios reprodujeron las versiones oficiales sobre

\footnotetext{
12 Estas acciones se inscribían en un movimiento social amplio y multiforme que, como respuesta a la escalada represiva desatada en 1966 y particularmente, con posterioridad al Cordobazo (1969), llevaron adelante en todo el país una multiplicidad de organizaciones de defensa y solidaridad con presos políticos, en un proceso que alcanzó un punto culminante hacia fines de 1972, cuando la magnitud de la "Masacre de Trelew" ubicó al problema de los presos políticos en el centro de la agenda política. Véase Eidelman, Ariel, "El PRT-ERP...", op. cit.

13 Pittaluga, Roberto, "La memoria según Trelew", Sociohistórica, 19/20, La Plata, 2006, págs. 81-111.

14 La ley 19.797 incorporaba un nuevo artículo al Código Penal, por el que cual "el que por cualquier medio difundiere, divulgare o propagare comunicaciones o imágenes provenientes de o atribuidas o atribuibles a asociaciones ilícitas o a personas o a grupos notoriamente dedicados a actividades subversivas o de terrorismo, será reprimido con prisión de seis meses a tres años”. LNP, Bahía Blanca, 23/8/72, “Artículo 212 del C. Penal”.
} 
lo sucedido. Sin embargo, no todo fue obra de la intimidación gubernamental; varios diarios se hicieron eco de los rumores militares ${ }^{15}$.

Este fue el caso de La Nueva Provincia $(L N P)^{16}$, el principal diario local. Al igual que otros medios de comunicación, tuvo vedada la entrada a la Base "Almirante Zar" ${ }^{17}$, pero un enviado especial pudo entrevistar a las autoridades del Comando de Emergencia de Rawson y a Samuel Somoza, secretario del juez de la Cámara Federal en lo Penal de la Nación ${ }^{18}$, Jorge Quiroga. Por otra parte, el 24, LNP y Canal 9 "Telenueva" lograron ingresar a "Puerto Belgrano", donde consultaron a las autoridades navales sobre el estado de salud de los heridos, registraron notas a los tres militantes y les tomaron las primeras fotografías, que aparecieron publicadas al día siguiente. A la prensa de Capital Federal, por su parte, le fue permitido el acceso un día después, mientras que a los familiares y abogados aún se les impedía entrar con el argumento de que no era recomendable según las prescripciones médicas ${ }^{19}$.

El 23 de agosto, el matutino dedicó varias notas a los hechos de la Base "Almirante Zar". Así eligió titular la nota principal: "Fueron muertos 15 guerrilleros que intentaban huir de Trelew. Otros cuatro resultaron heridos". Si bien se planteaba que las versiones de los hechos eran contradictorias, por lo que era difícil para la prensa reconstruir la situación, se reproducía la explicación oficial según la cual los "extremistas" "murieron cuando intentaron fugarse tomando algunos rehenes", "cayeron bajo las balas de las fuerzas de seguridad" en un "espectacular tiroteo". A partir de las fuentes militares, LNP informaba que cuando el capitán de corbeta Luis Emilio Sosa estaba haciendo una recorrida por las dependencias donde estaban alojados los "extremistas" fue rodeado por dos o tres de ellos que lo amenazaron de muerte y lo tomaron como rehén. Aquellos intentaron "copar" la sala de armas y consiguieron apoderarse de algunas para huir de la base. Entonces los 400 efectivos de guardia, "con un claro sentido de responsabilidad castrense", no vacilaron en hacer fuego contra los "terroristas" pese a poner en peligro la vida de su jefe, quien resultó herido. Esta "eficaz acción de represión", guiada por las consignas recibidas previamente, logró hacer fracasar la operación y culminó con la muerte de 15 "extremistas". Así, las condiciones de seguridad del lugar estuvieron garantizadas por "la severidad de las consignas y la tenaz subordinación" de la guardia, y no por la exclusión en celdas individuales o el aislamiento e incomunicación de los presos. Fue esa "aparente flexibilidad en el trato humano" lo que pudo haber inducido a aquellos a creer que la fuga era fácil ${ }^{20}$. Sin embargo, según las apreciaciones de Somoza publicadas un día después, los "extremistas" habrían sido alojados en la base por razones de seguridad ya que "era el único lugar donde se disponía del número adecuado de calabozos. No podían ser nuevamente reubicados en el penal" 21 . A

\footnotetext{
15 Pittaluga, Roberto, "La memoria según Trelew”, op. cit.

${ }^{16}$ Diario bahiense fundado en 1898 por Enrique Julio y propiedad de la familia Massot. La empresa fue ampliada con la adquisición, en 1958, de LU2 "Radio Bahía Blanca” y, en 1965, de Canal 9 "Telenueva”, convirtiéndose en la voz periodística hegemónica en la ciudad. Se destaca su discurso antiperonista y pro-militar. En 1976, las mismas fuerzas de seguridad reconocieron su importancia fundamental como único medio real de difusión y acérrimo enemigo del marxismo, del "tercermundismo" y del peronismo (Véase Zapata, Belén, Páginas Manchadas. Conflictividad laboral entre los gráficos y La Nueva Provincia en vísperas de la dictadura de 1976, Tesis de Licenciatura en Historia, Universidad Nacional del Sur, Bahía Blanca, 2008). En la actualidad, su director, Vicente Massot, se encuentra acusado por crímenes de lesa humanidad.

${ }^{17}$ LNP, Bahía Blanca, 24/3/72, "Cerrado hermetismo en la Base Aeronaval de Trelew".

18 Fuero anti-subversivo creado en mayo de 1971. Era un tribunal especial con jurisdicción federal, constituido por nueve jueces más un fiscal encargados de juzgar oralmente y en instancia única, una amplia gama de delitos que iban desde rebelión y atentados hasta secuestros y resistencia a la autoridad. Los camaristas eran designados por el propio gobierno de facto. Véase Chama, Mauricio, "Movilización y politización...”, op. cit.

${ }^{19}$ LNP, Bahía Blanca, 25/8/72, "Rechazan un recurso de amparo en favor de los heridos en Trelew". LNP, Bahía Blanca, 26/8/72, "Mejora el estado de los heridos".

${ }^{20}$ LNP, Bahía Blanca, 23/8/72, "Fueron muertos 15 guerrilleros que intentaban huir de Trelew".

${ }^{21}$ LNP, Bahía Blanca, 24/8/72, "Cerrado hermetismo...".
} 
continuación, la nota principal del 23 transcribía el comunicado del Comando de la Zona de Emergencia que agregaba a la narración anterior que el episodio se inició a las 3.30, que fue Mariano Pujadas quien atacó por la espalda al jefe de turno, logrando sustraerle el arma, que el hombre consiguió zafarse, fue atacado a tiros, y fue allí cuando la guardia contestó al fuego contra los reclusos que se "abalanzaban hacia la puerta de salida, encabezados por Pujadas"22. Además, un informe del enviado especial en Trelew incluyó las palabras de un mayor del Ejército, que planteaba que "el connato de fuga no había sido planeado, sino que obedecía a un acto espontáneo, ya que Pujadas, en un momento de desesperación, trató de neutralizar al oficial de la Armada que realizaba una inspección de rutina". Por lo tanto, "no habría existido apoyo exterior" ${ }^{\prime 23}$.

Las informaciones ofrecidas por el diario en los días siguientes se inscribían en la misma narrativa militar: se definía lo ocurrido como una "intentona" de evasión de la base aeronaval por parte de los detenidos y entendía las 16 muertes como el producto de un intenso enfrentamiento armado provocado por la agresión de los "extremistas" 24 . Para la construcción de este relato, se volvía sobre las razones que habrían motivado a los detenidos a una empresa imposible. Así, se citaba a Somoza, quien opinaba que el intento de fuga de un lugar aparentemente inexpugnable no era descabellado, dado que el pabellón donde estaban los presos se encontraba a relativamente poca distancia de la guardia de salida de la base, la cual, desde la lógica de los "extremistas" podía ser franqueada con ayuda de rehenes y armas ${ }^{25}$.

Al mismo tiempo, LNP respaldó la narración oficial resaltando el carácter de "terroristas"/ "extremistas" de las víctimas de Trelew y su peligrosidad. Así, publicó los antecedentes judiciales de los 19 "elementos" que protagonizaron los sucesos del 22 de agosto, detallando además de sus datos personales, las "organizaciones guerrilleras clandestinas" a las que pertenecían, las circunstancias de detención, los delitos por los que habían sido procesados, el tribunal interviniente, la fecha y el decreto por el cual fueron puestos a disposición del Poder Ejecutivo $\mathrm{Nacional}^{26}$. Con esta lectura coincidía un comunicado del III Cuerpo de Ejército, que expresaba que quienes habían perdido sus vidas eran delincuentes, asesinos -siendo una de sus víctimas el "humilde trabajador" que se desempeñaba como guardiacárcel en Rawson-, que se apropiaban de lo ajeno y pretendían imponer por la sangre ideas políticas que "no responden a la esencia del ser argentino"27. Según Somoza, las declaraciones que los testigos del copamiento del penal de Rawson presentaron al juez horas antes del incidente del 22 de agosto, permitieron comprobar que había sido Pujadas el responsable de los 13 disparos que acabaron con la vida del guardiacárcel, mientras Ana María Villareal había efectuado el tiro de gracia. Ese habría sido motivo suficiente para encabezar el desesperado intento de fuga ${ }^{28}$.

A pesar de la censura oficial, de la difusión por los medios masivos de la versión del "intento de fuga" y del aislamiento impuesto a los sobrevivientes, pronto se elaboraron y comenzaron a circular otros relatos sobre los hechos del 22 de agosto que cuestionaban o negaban la explicación oficial con el argumento de su inverosimilitud. La esposa de Bonet relataba que tan

\footnotetext{
${ }^{22}$ LNP, Bahía Blanca, 23/8/72, "Fueron muertos 15 guerrilleros...".

${ }^{23}$ LNP, Bahía Blanca, 23/8/72, "Considérase que no habría existido un apoyo exterior".

${ }^{24}$ LNP, Bahía Blanca, 24/8/72, "Asciende a 16 el número de extremistas fallecidos” y subnota "Llegaron a Rosario los restos de Carlos Del Rey"; LNP, Bahía Blanca, 25/8/72, "Rechazan un recurso de amparo..." y subnotas "Desmentido en la Base", "Informe oficial", "En General Roca".

${ }^{25}$ LNP, Bahía Blanca, 24/8/72, "Asciende a 16...".

26 LNP, Bahía Blanca, 23/8/72, "Vinculación de los terroristas con organizaciones clandestinas". LNP, Bahía Blanca, 24/8/72, "Los sobrevivientes están internados...".

${ }^{27}$ LNP, Bahía Blanca, 24/8/72, "Comunicado del III Cuerpo de Ejército".

${ }^{28}$ LNP, Bahía Blanca, 24/8/72, “Asciende a 16...”.
} 
pronto como se enteró de la noticia tuvo la "certeza interior" de que los compañeros no habían tratado de escaparse:

"yo digo esto no es verdad porque estaban desnudos, estaban desarmados [...] estaban incomunicados del exterior, y ese lugar es un lugar desértico, árido, en donde no bay un árbol para esconderse y no habia ninguna posibilidad del exterior ni ninguna idea de poder hacer algo en un lugar donde estaba rodeado por militares con todas las armas. O sea que era imposible. Y por otro lado, sabiendo quiénes eran estas personas [...] son 19 cuadros [...] eran incapaces de reaccionar a cualquier tipo de provocación porque ya sabian que eso era los que les esperaba, ${ }^{29}$.

Asimismo, en sus escalas en Bahía Blanca los días 23 y 24 de agosto, el abogado Sandler dijo a LNP que las fuerzas armadas tenían "la responsabilidad pública de explicar por qué no se permitió a los familiares de los detenidos comunicarse con ellos luego del copamiento del penal de Rawson", medida que, a la luz de los últimos sucesos, resultaba "muy sugestiva"30. También manifestó que en todo lo ocurrido hubo un "evidente proceso de ocultamiento" 31 .

Por su parte, desde el mismo 22 de agosto el movimiento estudiantil manifestó su lectura frente a los hechos de la Base "Almirante Zar". Una asamblea celebrada ese día en la UNS los calificó de "fusilamiento" y un cartel colocado en los mástiles del playón del edificio de Avenida Alem, llevaba la inscripción "14 compatriotas fusilados por la dictadura" 32 . El 24, un volante firmado por la "Asamblea estudiantil Guillermo López" calificaba los sucesos como "masacre" y los denunciaba como parte de la escalada represiva del régimen, ligándolos a las arbitrariedades sufridas en los últimos meses por los activistas locales que engrosaban la lista de los presos políticos. Según los estudiantes, el "vandálico suceso de Trelew"

"muestra una vez más la dictadura y el G.A.N. Los 16 compañeros asesinados y 3 heridos en la Base Naval de Trelew son un trágico testimonio más de los métodos represivos del régimen. El "intento de fuga" de los detenidos (aislados completamente e incomunicados) por el cual se los mata, es una clara mentira a la vista de todos, que nos muestra hasta qué punto son capaces de premeditar los hechos para eliminar a los detenidos políticos que por centenares pueblan las cárceles argentinas. En Bahía Blanca, hace ya un año, la dictadura encarceló a un compañero, Guillermo López Chamadoira, recluido en la cárcel de Resistencia. Estos hechos nos demuestran los métodos con los que la dictadura asesina pretende detener el ascenso de las luchas de la clase obrera y los trabajadores explotados. Que nadie se engañe: la masacre de Trelew es la culminación de un proceso en el que se ha incrementado la legislación represiva, se han puesto bajo el control militar las cárceles, modernizan los instrumentos de tortura, utilizando el ejército y ahora la marina para nutrir a la policía en la represión directa de todo tipo de movilización popular. Pero si debe apoyarse en las bayonetas es porque tienen en contra al conjunto de la población que ha comenzado a dar una respuesta masiva" 33 .

\footnotetext{
${ }^{29}$ Entrevista a Alicia Leichuk, Radio Futura, 16/5/11. Disponible en (acceso 11/3/14): http://radiofuturalaplata.blogspot.com.br/2011/05/nuevo-impulso-para-el-enjuiciamiento-de.html. ${ }^{30}$ LNP, Bahía Blanca, 23/8/72, "Pasó por Bahía Blanca...".

${ }^{31}$ LNP, Bahía Blanca, 24/8/72, "Regreso de Sandler".

32 Telegrama firmado por el Crio. Trujillo s/f; "Repercusión de los sucesos de Trelew en Bahía Blanca” del 22/8/72, Mesa "D(s)", Carpeta Varios, Legajo 383, Tomo 1. Fondo DIPPBA. Y LNP, Bahía Blanca, 23/8/72, "Concentración en el Instituto Juan XXIII".

33 Volante firmado por la "Asamblea estudiantil Guillermo López”, Mesa “D(s)”, Carpeta Varios, Legajo 383, Tomo 1. Fondo DIPPBA
} 
Además, en una asamblea celebrada el 25 de agosto en el Instituto "Juan XXIII", una estudiante se refirió a los hechos de Trelew como "brutales asesinatos y fusilamientos", destacando que "habían sido preparados y que incluso el oficial de marina llevaba el arma con balas de fogueo" 34 .

Por otro lado, ese día los abogados defensistas locales ofrecieron una conferencia de prensa en la que indicaron que nadie creía en las explicaciones oficiales sobre la "masacre de Trelew" y rebatieron las afirmaciones de las autoridades navales en cuanto a que los familiares habían podido ver a los detenidos ${ }^{35}$. En este sentido, los abogados también recurrieron a sus redes personales para desmentir esa información y buscar apoyos locales para concretar la visita a los heridos. En este marco, los padres de las víctimas se reunieron con sacerdotes liberacionistas para interiorizarlos sobre lo ocurrido. Así lo evocaba Zamorano:

"nos enteramos por lo siguiente: familiares de...no sé si fue un sobreviviente, acudieron al arzobispado y twieron una entrevista, Segovia, algunos de nosotros y habrá sido Santecchia y yo y algunos más, en el bote $\beta^{6}$ que estaba enfrente al arzobispado, en la esquina. Abi estuvo una compa... los papás de uno de los muertos o... Y abi supimos lo que habia pasado, porque no se sabia'"37.

El 26 de agosto se concretó una audiencia ${ }^{38}$ entre los familiares y el recientemente consagrado Monseñor Jorge Mayer, gracias a la mediación del secretario canciller. Al respecto, Segovia explicaba que entonces no había restricciones para hablar con la máxima autoridad eclesiástica. Pero cuando los abogados locales, encabezados por Facchini -que era amigo del sacerdote por ser ambos oriundos de Punta Alta-, se acercaron por primera vez al Arzobispado, se toparon con un capellán de la Marina que les dijo que Mayer se encontraba en Buenos Aires. Sin embargo, Facchini volvió a la Curia a la mañana siguiente, donde encontró a Segovia, quien lo contactó inmediatamente con el arzobispo ${ }^{39}$. La audiencia contó con la participación de algunos presbíteros, entre ellos, el secretario canciller, que se ocupó de avisar a los medios de comunicación para que registraran el ingreso de las personas al edificio. Durante la misma, los padres de los heridos informaron a Mayer sobre la situación de aislamiento en la que permanecían los militantes, contradiciendo la información que el jefe de la Base le había dado a aquél por teléfono, causándole con ello gran sorpresa e inquietud. Y si bien no consiguieron que el arzobispo aceptara acompañarlos al hospital, lograron su palabra de que intercedería por ellos en "Puerto Belgrano". Segovia relataba:

"el papá de este chico Haidar dijo: 'mire, yo soy radical, Monseñor, soy católico dominical, practico. Mi hijo no. Pero yo no comparto algunas posturas de mi bijo aunque yo lo respeto porque él está convencido de un ideal. Y yo estoy tratando de defenderlo, de verlo, porque no lo he podido ver. Entonces yo dudo de lo que está pasando. No sé si mi bijo vive o no vive'. 'Pero usted...'. 'No Monseñor, yo le puedo asegurar que no los hemos visto nosotros'. 'Pero iecómo?! Bueno, yo me voy a ocupar entonces de esto'"»o.

Finalmente, el encuentro entre los heridos y sus familiares se concretó el 28 de agosto. Fue luego de esa visita, breve y mediada por la prohibición de establecer contacto físico y por la presencia

\footnotetext{
34 Informe titulado “Asamblea de estudiantes del Instituto del Profesorado Juan XXIII" del 25/8/72, Mesa A, Estudiantil, Localidad Bahía Blanca, Legajo N 47. Fondo DIPPBA.

35 Telegrama s/f, "Informe sobre extremistas heridos internados..." 25/8/72, "Informe relacionado conferencia de prensa abogados defensores elementos extremistas internados hospital naval Puerto Belgrano" 27/8/72. Fondo DIPPBA.

36 Allí se alojaron el 29 los abogados defensistas provenientes de Buenos Aires y de Córdoba que tomaron contacto con los colegas locales. "Ampliar Memorando Dpto. "D” 104”, del 29/8/72, Mesa “D(s)", Carpeta Varios, Legajo 383, Tomo 1. Fondo DIPPBA.

37 Entrevista a José Zamorano, Moreno, 19/9/09.

38 Boletín Eclesiástico, Bahía Blanca, octubre-diciembre 1972.

${ }^{39}$ Entrevista a Hugo Segovia, Mar del Plata, 27/5/10.

${ }^{40}$ Entrevista a Hugo Segovia, Mar del Plata, 27/5/10.
} 
militar, que la hermana y la esposa de Haidar, y el padre de Camps hicieron pública una declaración -firmada en Bahía Blanca- en la que difundieron el relato de los sobrevivientes, contradiciendo la versión oficial:

"[los detenidos] fueron sacados por personal militar de sus celdas y alineados en el pasillo cerrado que corre entre las mismas. Suponían que se trataría de uno de los habituales interrogatorios que a diario practicaba personal de policía federal, llamándoles no obstante la atención el hecho de sacarlos en forma conjunta puesto que los anteriores interrogatorios se habían efectuado en forma individual. Una vez alineados en ese lugar, el mismo personal militar sin previo aviso, ni incidente de ninguna naturaleza, comenzó a hacer fuego sobre los detenidos. En esa circunstancia varios de estos lograron refugiarse en las celdas abiertas a sus espaldas, siendo en esos lugares, en los que oficiales de marina penetraron disparando a quemarropa, pudiendo notar que la misma operación se repetía en las celdas cercanas a las que ocupaban en ese momento. Tanto Camps como Haidar manifestaron que en momentos de refugiarse en dichas celdas se hallaban ilesos" $"$.

\section{Lo que se hizo}

El mismo 22 de agosto se iniciaron las gestiones de los abogados locales. Acompañados de un médico puntaltense y Alicia Leichuk, se presentaron en "Puerto Belgrano" para "hacer ejercicio del derecho de defensa" y revisar a los heridos, pero no lograron verlos ni obtener información ${ }^{42}$. En consecuencia, los letrados presentaron al juez federal de Bahía Blanca Carlos Romero del Prado un recurso de amparo en favor de los jóvenes con el objeto de preservar su integridad física. Para los profesionales, el hecho de que los sobrevivientes estuvieran en la jurisdicción de las mismas autoridades que habían intervenido en los episodios de Trelew no les ofrecía garantías de supervivencia. Por su parte, el juez dispuso que un médico forense se trasladara al hospital para examinar a los heridos y al día siguiente, rechazó el recurso al considerar que el derecho que se pretendía preservar se encontraba plenamente asegurado, en cuanto que con un informe proporcionado por el Comandante de Operaciones Navales, vicealmirante Rubén Giovedoni, había quedado establecido que los traslados al hospital naval habían sido autorizados por el juez Quiroga, a disposición de quien se encontraban para su necesaria atención médica. Además, para el magistrado, el informe del médico de ese Tribunal acreditaba que todas las personas se encontraban bajo tratamiento y control médico adecuado ${ }^{43}$.

Asimismo, el 24 los defensistas requirieron a Quiroga que se levantara la incomunicación, que se trasladara a los militantes a un hospital de jurisdicción civil y que se delegara en un juez federal de Bahía Blanca la tarea de tomarles declaración. Al mismo tiempo, junto a abogados de Buenos Aires y Santa Fe, solicitaron al mismo juez la instrucción de un sumario al vicealmirante Giovedoni por desobediencia, incomunicación indebida, abuso de autoridad y violación de los deberes de funcionario público ${ }^{44}$.

\footnotetext{
${ }^{41}$ Mesa "D(s)", Carpeta Varios, Legajo 383, Tomo 1. Fondo DIPPBA.

${ }^{42}$ LNP, Bahía Blanca, 23/8/72, "Pasó por Bahía Blanca...".

${ }^{43}$ En efecto, ese día, el Comando de Operaciones Navales emitió un comunicado donde daba cuenta de la situación de los heridos "en el intento de fuga": los jóvenes habían sido intervenidos quirúrgicamente, examinados por el médico forense y se encontraban a disposición del juez Quiroga, quien había dispuesto levantar la incomunicación; tan pronto como lo permitiera su estado de salud podrían ser visitados por sus familiares directos y por los abogados defensores, y cuando lograran recuperarse serían reintegrados al penal de origen o el lugar donde dispusiera el juez. LNP, Bahía Blanca, 24/8/72, "Recurso de amparo"; LNP, Bahía Blanca, 25/8/72, "Recurso desestimado", "Informe oficial". "Informe sobre extremistas heridos..." del 25/8/72, Mesa "D(s)", Carpeta Varios, Legajo 383, Tomo 1. Fondo DIPPBA

${ }^{44}$ LNP, Bahía Blanca, 25/8/72, "Telegrama". Telegrama s/f elevado a la DIPPBA e "Informe sobre extremistas heridos..." del 25/8/72, Mesa "D(s)", Carpeta Varios, Legajo 383, Tomo 1. Fondo DIPPBA.
} 
A día siguiente, reclamaron ante los jefes navales para que los familiares y defensores pudieran visitar a los heridos. Cuando el 28 de agosto los primeros lograron concretarlo aunque no así los segundos, intervino el Colegio de Abogados local, demandando el respeto del ejercicio profesional de los colegas ${ }^{45}$.

Entre el 22 y el 28 de agosto, la intervención de los sectores católicos renovadores estuvo motivada por la urgencia de preservar la vida de los sobrevivientes, así como por la necesidad de denunciar lo sucedido. Sobre la primera cuestión, Sarmiento planteaba: "acá en Punta Alta enseguida se conoció el tema y el primero que larga la alarma es 'Coco' [Segovia], porque el tema era instalar enseguida que acá estaban los tres sobrevivientes antes que los mataran" ${ }^{\prime 46}$.

En este sentido, resultaba vital "interesar" al arzobispo ${ }^{47}$ en el asunto y comprometerlo en las gestiones destinadas a lograr que los familiares y los abogados pudieran entrar en "Puerto Belgrano". De allí la mediación de los sacerdotes para concretar la audiencia con Mayer. Al mismo tiempo, estos presbíteros organizaron una misa por las víctimas y los heridos, para repudiar los asesinatos. Zamorano daba relevancia a la "denuncia de la masacre" como un hito en la consolidación de este grupo sacerdotal: "tomamos una postura muy clara respecto al asesinato de la masacre de Trelew (sic), los curas, el grupo nuestro [...] como que abi ya nos fuimos definiendo mucho" ${ }^{\text {*8 }}$. Y Segovia resaltaba el sentido de la iniciativa a la luz de la situación de los sobrevivientes y de sus familiares: se pedía "por la libertad de esos chicos" ".

El oficio religioso tuvo lugar el mismo 26 de agosto a las 21 horas en "Nuestra Señora de Lourdes" y estuvo a cargo de más de una docena de sacerdotes. La homilía fue preparada entre todos los presbíteros renovadores pero, al momento de hablar, tuvieron especial cuidado en elegir a aquellos que estaban menos expuestos públicamente o, en palabras de Sarmiento, los más "moderados" o "tranquilos" del grupo. Entonces, predicaron Stocchetti y Sarmiento junto al párroco Eliberto Baudry y el Vicario General de la Arquidiócesis, Rómulo García, quien presidió la celebración ${ }^{50}$. Así explicaba Segovia su negativa a hablar:

"Primero, porque estaba sumamente cuestionado [...] Yo no quise tal vez por precaución, sabiendo cómo venía la mano ¿no? Sabiendo que la Base Naval era...Para colmo mi papá era militar...se habia jubilado, habia fallecido ya ino?, o sea que era casi una traición para ellos, que un bijo de un militar fuera un 'guerrillero' como aparecía yo, 'altamente peligroso'"51.

En un marco en el que las autoridades eclesiásticas ya habían puesto reparos para la realización de la misa, se quería garantizar que la misma se llevara adelante como un signo significativo de la Iglesia a nivel local:

\footnotetext{
45 Telegrama s/f, "Informe sobre extremistas heridos..." 25/8/72, "Informe relacionado conferencia de prensa abogados defensores..." 27/8/72, “Ampliando Memorando Dpto. D 104” del 29/8/72, Mesa "D(s)", Carpeta Varios, Legajo 383, Tomo 1. Fondo DIPPBA.

${ }^{46}$ Entrevista a Miguel Sarmiento, Punta Alta, 11/2/11.

47 "Informe relacionado conferencia prensa abogados defensores..." del 27/8/72, Mesa "D(s)", Carpeta Varios, Legajo 383, Tomo 1. Fondo DIPPBA.

48 Entrevista a José Zamorano, Moreno, 19/9/09 y 2/9/11. Más allá de las distintas actividades que estos sacerdotes desarrollaban, se fueron acercando por sus afinidades teológicas y pastorales, y comenzaron a reconocerse y a ser reconocidos como un grupo. Se identificaban con los principales lineamientos del MSTM, aunque sólo Zamorano, Sarmiento, Stocchetti y Barreto formaron parte del movimiento.

${ }^{49}$ Entrevista a Hugo Segovia, Mar del Plata, 27/5/10.

50 Entrevistas a José Zamorano, Moreno, 19/9/09 y 2/9/11; Hugo Segovia, Mar del Plata, 27/5/10; Miguel Sarmiento, Punta Alta, 29/11/10 y 11/2/11.

${ }^{51}$ Entrevista a Hugo Segovia, Mar del Plata, 27/5/10.
} 
"García fue el que autorizó y que se propuso encabezar una misa concelebrada siempre y cuando fuésemos moderados en las homilías e involucráramos a todos: no solamente a los que llamaban los guerrilleros muertos sino también a los soldaditos que habian matado en la cárcel, que fuera una misa contra la violencia en general, sin tomar partido por ninguna de las partes. Se lo aceptamos. Lo importante era que babia que salir al frente -estaban los tres chicos acá en la Base internados-, y habia que hacer algún gesto ${ }^{, 52}$.

Probablemente, esta cuestión haya estado presente al momento de hacer la convocatoria. En el volante de invitación a la celebración, la JUC planteaba la obligación de alzar la voz frente a los sucesos de Trelew y Rawson "que han costado la vida de 17 personas (un guardiacárcel y 16 presos políticos), hechos que son una manifestación más de la violencia que impera en todos los órdenes de la realidad argentina". Pero a continuación, se ponía el acento en la impugnación del accionar represivo, planteando su necesidad "como cristianos" de expresar "un signo de esperanza por la vida de los heridos" y de denunciar "la total ausencia de respeto a la dignidad de la persona humana por parte de quienes detentan el poder" ${ }^{\prime 23}$.

La iglesia recibió entonces a una multitud de personas, en su mayoría jóvenes, que incluían a los integrantes de los grupos laicales bahienses y puntaltenses ${ }^{54}$. Según los servicios de inteligencia, entre los asistentes, había "activistas estudiantiles que pretendían iniciar en el lugar una huelga de hambre, en señal de protesta por aquellos hechos, pero la misma no se concretó" ${ }^{55}$.

En efecto, durante esos primeros días posteriores a la "Masacre", también se destacó la movilización de los estudiantes bahienses en repudio a los sucesos de la Base "Almirante Zar". En la UNS, el 22 los alumnos izaron a media asta una bandera argentina con una tela negra colocada en el lugar del sol y otra a manera de gallardete. Luego, levantaron distintos cursos e invitaron a una asamblea que resolvió realizar una marcha de silencio al día siguiente ${ }^{56}$. El 23 los estudiantes circularon frente al Rectorado, bajo la vigilancia de la policía, mientras otros levantaron clases y realizaron una asamblea en el edificio de Alem. Desde allí, unos 200 jóvenes, que portaban una bandera argentina con crespón, se dirigieron hacia el Instituto "Juan XXIII" y al sufrir la intervención policial que los dispersó, se refugiaron en aquel edificio, donde dialogaron con los alumnos ${ }^{57}$.

El 24 de agosto 150 estudiantes se congregaron en la sede de calle Alem, retiraron bancos de las aulas y los ubicaron en la vía pública, donde almorzaron más tarde debajo de un cartel de la "Asamblea estudiantil de Bahía Blanca" que rezaba: "Repudiamos la Masacre de Trelew", "Libertad a Guillermo y demás presos políticos" y "Abajo la dictadura asesina" 58 . Asimismo, la "Asamblea estudiantil Guillermo López" convocó a los sectores estudiantiles y populares a "levantar su voz de repudio", uniéndose a un paro activo y a un acto común al día siguiente en las escalinatas de la $\mathrm{UNS}^{59}$.

\footnotetext{
52 Entrevista a Miguel Sarmiento, Punta Alta, 11/2/11.

53 JUC, “A los compañeros estudiantes", Mesa “D(s)", Carpeta Varios, Legajo 383, Tomo 1. Fondo DIPPBA.

54 Entrevista a Miguel Sarmiento, Punta Alta, 29/11/10; y a Hugo Segovia, Mar del Plata, 27/5/10.

55 "Misa por los caídos en Trelew" del 27/8/72, Mesa "D(s)", Carpeta Varios, Legajo 383, Tomo 1. Fondo DIPPBA.

56 Telegrama firmado por el Crio. Trujillo s/f; "Repercusión de los sucesos..." del 22/8/72, Mesa "D(s)", Carpeta Varios, Legajo 383, Tomo 1. Fondo DIPPBA. Y LNP, Bahía Blanca, 23/8/72, "Concentración en el Instituto Juan XXIII".

57 LNP, Bahía Blanca, 24/8/72, "Incidentes estudiantiles". "Informe sobre extremistas heridos..." del 25/8/72, Mesa "D(s)", Carpeta Varios, Legajo 383, Tomo 1. Fondo DIPPBA.

58 LNP, Bahía Blanca, 25/8/72, "Demostraciones estudiantiles". "Informe sobre extremistas heridos..." del 25/8/72, Mesa “D(s)", Carpeta Varios, Legajo 383, Tomo 1. Fondo DIPPBA.

59 Volante firmado por la "Asamblea estudiantil Guillermo López”, Mesa “D(s)”, Carpeta Varios, Legajo 383, Tomo 1. Fondo DIPPBA.
} 
Por su parte, los alumnos del Instituto "Juan XXIII" también protagonizaron diversas iniciativas de protesta una vez conocida la noticia. Durante la tarde del 22 de agosto, levantaron cursos y llevaron a cabo una asamblea que trató los sucesos de la madrugada previa y resolvió realizar una misa en la capilla del establecimiento. La misma, oficiada por Barreto "por los argentinos muertos en Trelew", contó con la participación de más de un centenar de estudiantes. Alrededor de las 21 horas, los jóvenes salieron a la calle portando velas encendidas y se concentraron en las escalinatas del edificio para expresar su homenaje a los 16 militantes, iniciativa que congregó a unas 50 personas, según los cálculos de los agentes de inteligencia. Poco después, la manifestación fue dispersada y tres jóvenes fueron detenidos por la policía ${ }^{60}$.

Durante la concentración, los estudiantes distribuyeron una declaración firmada por la "Asamblea de estudiantes del Juan XXIII" que, según los servicios de inteligencia, había sido elaborada en el colegio salesiano Don Bosco con la participación de "sacerdotes terceristas" ${ }^{\text {" }}$ En ella, profesores y estudiantes se definían frente a lo ocurrido. Las muertes de los jóvenes -y aquí, al igual que la JUC, incluían las de "esos agentes y esos soldados que son mandados a pelear contra nosotros, sin dejarles pensar que son parte del pueblo igualmente que nosotros"- llamaban a la reflexión, a la vez que a "reaccionar", a "desterrar el 'no te metas", a "comunicarse e integrarse" para acabar con la "miseria humana que nos rodea":

"Queremos atacar las causas de esta situación insoportable, insostenible, que ha llevado a este estado de guerra civil. Aquí no podemos atacar métodos y medios. Aquí debemos adherirnos a esas motivaciones, las mismas que tenemos nosotros, producto de lo mismo que sentimos y que es HAMBRE, LA DESOCUPACIÓN, LA INJUSTICIA, Y LA CADA VEZ MAYOR ALTA DE LIBERTAD. Esas son las causas, esas causas que son nada más ni nada menos que violencia legalizada y que debe repugnarnos a todos" ${ }^{\text {2 } 2}$.

El 25 de agosto, los estudiantes del "Juan XXIII" celebraron otra asamblea para informar sobre la detención de los compañeros durante el acto del 22 y analizar la situación del propio movimiento estudiantil durante los últimos meses. Allí, se abordaron los sucesos de Trelew y se distribuyó el volante de la "Asamblea Guillermo López" que convocaba al acto en las escalinatas de la $\mathrm{UNS}^{63}$.

Ahora bien, ¿qué iniciativas llevaron adelante los actores locales a partir del 28 de agosto? Una vez hecho público el documento de los familiares, tanto los sectores católicos renovadores como los estudiantiles se ocuparon de hacer circular el relato de Haidar, Camps y Berger, volviendo a cuestionar las explicaciones oficiales y el rol de la prensa en su difusión. Así, un informe de los agentes de inteligencia mencionaba que el mismo sacerdote que había oficiado una misa por "los argentinos muertos en Trelew" distribuyó volantes "con supuestas declaraciones de los familiares de los extremistas heridos". El parte también aludía a la homilía de Zamorano del 10 de septiembre, referida a la "prostitución de la verdad" de los medios informativos, que distorsionaban los hechos a su "gusto", por lo que los católicos debían estar atentos "para establecer el verdadero significado de las informaciones" ${ }^{\text {. Si }}$ Si bien aquí no hay referencias

\footnotetext{
60 "Repercusión de los sucesos..." del 22/8/72, Mesa “D(s)", Carpeta Varios, Legajo 383, Tomo 1. Fondo DIPPBA. Y LNP, Bahía Blanca, 23/8/72, "Concentración en el Instituto Juan XXIII". Entrevista a Patricia -entonces integrantes de la JUC y alumna del Instituto-, Bahía Blanca, 19/5/08.

61 "Repercusión de los sucesos..." del 22/8/72, Mesa "D(s)", Carpeta Varios, Legajo 383, Tomo 1. Fondo DIPPBA.

${ }^{62}$ Volante firmado por la “Asamblea estudiantes el Juan XXIII”, Mesa “D(s)”, Carpeta Varios, Legajo 383, Tomo 1. Fondo DIPPBA.

63 Informe titulado "Asamblea de estudiantes del Instituto..." del 25/8/72, y volante titulado "Asamblea estudiantil”, Mesa A, Estudiantil, Localidad Bahía Blanca, Legajo N 47. Fondo DIPPBA.

64 “Memorando Depto. 'C’ $N^{\circ}$ 430. Cumplimiento despacho 'C' $\mathrm{N}^{\circ} 2230$ ” del 13/9/72, Mesa "Referencia", Legajo $\mathrm{N}^{\circ}$ 15281, Tomo V. Fondo DIPPBA.
} 
explícitas a LNP o al acontecimiento del 22 de agosto, debe considerarse que el contexto en el que fueron emitidas estaba atravesado por sus repercusiones.

Por otra parte, en una asamblea realizada en la UNS a principios de septiembre, los universitarios manifestaron que el testimonio de los sobrevivientes y las denuncias acerca del estado de los cadáveres con signos de tortura eran "una muestra más de lo que una camarilla militar está dispuesta a hacer con tal de no renunciar a sus ‘altos y altruistas fines"”. En consecuencia, exhortaban al estudiantado a manifestar su repudio frente a la injusticia, la represión, la "tortura y muerte de 16 compañeros" y la incomunicación sufrida por los heridos, válida para familiares y abogados pero no para Coordinación Federal o la prensa. Y entendían que este estado de cosas sólo podía enfrentarse mediante "una lucha frontal organizada y consecuente contra esta dictadura que sirve a los intereses capitalistas y en defensa de ellos apelan a la violencia como único medio para perpetuarse en el poder" ${ }^{35}$.

En esos días, otro volante transcribía la declaración del 28 de agosto y postulaba que ésta venía a confirmar que en Trelew se había consumado un asesinato y que había sido ocultado por un régimen en descomposición y carente de legitimidad:

"Las autoridades elaboraron una mentira enorme con respecto a los hechos ocurridos en Trelew. Es una mentira más, fiel reflejo del inexorable derrumbe de la dictadura militar. Pretendieron hacerla "correr" y como refuerzo, emitieron un decreto-ley prohibiendo por cualquier medio la divulgación de hechos o imágenes "subversivas". Pero (como siempre) la mentira tiene patas cortas. La verdad se supo de labios de los propios protagonistas que vinieron a corroborar lo que el PUEBLO ya sabía: a los detenidos en Trelew los asesinaron a mansalva. AL PUEBLO ya no se lo puede engañar [...] BASTA DE TORTURAS! BASTA DE MUERTES! BASTA DE MISERIA! NO SEAMOS CÓMPLICES CON NUESTRO SILENCIO",66.

En este marco, los estudiantes profundizaron su lucha por la liberación de los presos políticos y confluyeron con la militancia de colectivos artísticos en pleno proceso de "radicalización". Como ha reconstruido Vidal ${ }^{67}$, el 27 de octubre se celebró una asamblea en la UNS por la constitución de un "tribunal popular antirrepresivo" destinado a lograr "la libertad del estudiante Guillermo López Chamadoira y todos los presos políticos", que congregó a cientos de estudiantes, intelectuales, obreros y artistas, y recibió la adhesión de partidos políticos, la Escuela de Servicio Social, agrupaciones estudiantiles universitarias y secundarias, gremiales, teatrales, de derechos humanos y de abogados de presos políticos ${ }^{68}$. El tribunal allí constituido, integrado por seis estudiantes de diferentes tendencias políticas y un "fiscal" -el abogado entrerriano, fundador del PCR y defensor de presos políticos Jaime Lipovetsky, quien participó de la asamblea como "invitado especial"- resolvió la organización de un encuentro artístico bajo la consigna de "libertad de los 1200 presos políticos, derogación de la legislación represiva, estado de sitio y pena de muerte", cuya recaudación sería destinada a la ayuda de los presos políticos.

\footnotetext{
${ }^{65}$ Volante firmado por la "Asamblea estudiantil Guillermo López" del 7/9/72, Mesa "D(s)", Carpeta Varios, Legajo 383, Tomo 1. Fondo DIPPBA.

${ }^{66}$ Volante "La mentira de patas cortas" del 25/8/72, Mesa A, Estudiantil, Localidad Bahía Blanca, Legajo N 47. Fondo DIPPBA.

67 Vidal, Ana, Experiencias del teatro militante en Babia Blanca, 1972-1978, Tesis de doctorado en Historia, Universidad Nacional del Sur, Bahía Blanca, 2016.

${ }^{68}$ Incluyó a la Liga Argentina por los Derechos Humanos y a los Abogados en contra de las leyes Represivas (sic). Véase Vidal, Ana, Experiencias del teatro militante en Babia Blanca..., op. cit.
} 
Para ello, se formó una "Coordinadora de Artistas Bahienses", compuesta por tres agrupaciones que comenzaban a mostrar signos de "politización" -entre ellas, Teatro "Alianza" "99-, que logró la adhesión de un gran número de grupos que estaban ubicados en diferentes sectores del campo cultural, pertenecían a diversas disciplinas y representaban variados posicionamientos estéticos. Así, el festival, concretado en el salón de la Asociación Empleados de Comercio ${ }^{70}$, reunió a casi dos mil personas y contó con artistas plásticos, bailarines, músicos, poetas y conjuntos teatrales. "Alianza" puso en escena un trabajo en el que combinó las declaraciones oficiales y los testimonios de los sobrevivientes de la "Masacre de Trelew" con poemas, pequeñas escenas y música, mezclando la canción de protesta de Violeta Parra con el Himno a la Alegría de Beethoven, la expresión oral con la corporal, la información escéptica con el testimonio desgarrado ${ }^{71}$. Con esta presentación, la agrupación inauguraba la metodología de la "creación colectiva", que implicaba el trabajo mancomunado de todos los participantes de la obra en la investigación de campo -con una rigurosa búsqueda y análisis de fuentes históricas y teóricas- y crítica de textos, y su puesta en escena, privilegiando hechos significativos de las luchas populares, de modo de ofrecer el teatro como herramienta para su toma de conciencia ${ }^{72}$.

Otra de las decisiones del tribunal fue la realización de pintadas en toda la UNS con el rostro de López Chamadoira y consignas por su libertad, que se concretaron durante el mes de noviembre y diciembre ${ }^{73}$.

\section{Reflexiones finales}

Ahora bien, ¿cómo fue construida la significación del acontecimiento de Trelew en Bahía Blanca en los días posteriores? Como hemos visto, la prensa local se hizo eco de la narración militar en el marco de la censura impuesta por la dictadura de Lanusse, e informó que 16 "terroristas" de alta peligrosidad, detenidos en la Base "Almirante Zar", habían sido abatidos en un nuevo intento de fuga. Más allá de las medidas gubernamentales, $L N P$ asumió un compromiso con el discurso de las fuerzas armadas y de seguridad, como lo hizo en otros momentos clave de la historia argentina ${ }^{74}$. Esto se puso de manifiesto en el modo en que el matutino abordó las repercusiones de la "Masacre" en la ciudad: si comparamos el parte que los agentes de inteligencia locales elevaron a sus superiores el 25 de agosto con las notas del diario del mismo día, constatamos que se trata prácticamente de los mismos textos, lo que resulta sugerente independientemente de cuál haya sido la versión original.

Sin embargo, en contraposición a las explicaciones oficiales y a las nominaciones que desplegó el multimedios, ni bien se conoció la noticia de lo ocurrido en Trelew, los abogados, los sectores católicos liberacionistas y los estudiantes locales leyeron el hecho como una "masacre", un "fusilamiento" y un "asesinato". Siguiendo a Pittaluga, el primer término se fue imponiendo como parte de la lucha por el sentido del acontecimiento pues su capacidad de significación

\footnotetext{
69 Surgido en Punta Alta en 1966, se radicó prontamente en Bahía Blanca, donde se distinguió al asumir un posicionamiento vanguardista. En 1972, parte de sus integrantes ingresaron al PCR y la agrupación pasó a definir su teatro en función del proceso político revolucionario, siendo el "Festival por la libertad" un hito en ese derrotero Véase Vidal, Ana, Experiencias del teatro militante en Babia Blanca..., op. cit.

${ }^{70}$ Fue sede de varias actividades de la Juventud Peronista recientemente creada. En la comisión directiva del sindicato, se destacó Ezequiel Crisol, militante de la resistencia peronista en la ciudad y secretario de la CGT Regional hasta 1971. Véase Zapata, Belén, Andamios de experiencias..., op. cit.

71 Véase Aguirre, Coral, Memorias del teatro combatiente: Teatro Alianza, Teatro para el Hombre y Teatro Laboratorio Babia Blanca 1969-1989, Bahía Blanca, EDIUNS, 2015.

72 Véase Vidal, Ana, Experiencias del teatro militante en Babia Blanca..., op. cit.

73 Véase Bonavena, Pablo, "Notas sobre el movimiento estudiantil...", op. cit.; Romero Wimer, Fernando y Becher, Pablo, "Los estudiantes y las luchas de calles...", op. cit.

${ }^{74}$ Véase Montero, Lorena, "Memorias del golpe en La Nueva Provincia”, en Cernadas, Mabel y Marcilese, José (ed.), Cuestiones políticas, socio-culturales y económicas del Sudoeste Bonaerense, Archivo de la memoria, UNS, Bahía Blanca, 2006.
} 
introducía un quiebre decisivo en los relatos militares sobre lo sucedido. Hablar de "masacre" suponía pensar en una matanza de seres imposibilitados de defensa y, a la vez, su carácter planificado, lo que se amalgamaba con cierta perplejidad frente a la desmesura represiva ${ }^{75}$. En este sentido, una estudiante subrayaba en asamblea que se trataba de hechos "brutales", "preparados" por la Marina. Una vez conocido el relato de los sobrevivientes, los alumnos del Instituto salesiano entendían que aquél confirmaba que los militantes habían sido asesinados "a mansalva". Y los universitarios hablaban de "sucesos vandálicos" perpetrados contra detenidos totalmente aislados e incomunicados, lo que suponía que la dictadura había "premeditado los hechos para eliminar a los detenidos políticos".

Durante los momentos posteriores al crimen, el argumento utilizado por los familiares y los actores locales para desmentir la versión oficial fue la inverosimilitud del intento de evasión de la base militar en las condiciones de seguridad en las que se encontraban los presos políticos que, además, habían entregado sus armas días antes. Así lo manifestó Alicia Leichuk. También para los estudiantes, el aislamiento de los militantes convertía el "intento de fuga" en una "clara mentira". Según los abogados porteños, el relato militar resultaba difícil de creer dada la voluntad de ocultamiento presente en las medidas adoptadas por los jefes navales a partir del 15 de agosto. También los letrados locales manifestaron públicamente que nadie creía en las explicaciones dadas por las fuerzas armadas.

Después de concretarse la visita de los familiares al hospital, el rechazo de la palabra oficial estaba respaldado por el testimonio de los sobrevivientes. A partir de entonces, los estudiantes, los sectores liberacionistas y los artistas que compartían una concepción militante emprendieron acciones marcadas por el imperativo de denunciar lo que realmente había ocurrido, así como su ocultamiento por parte de las autoridades militares y la prensa. Se intentaba construir un relato que expusiera la verdad, aferrándose al decir de los protagonistas. Al igual que las publicaciones analizadas por Pittaluga, los actores bahienses asumieron la tarea de disputar la coacción dictatorial a la palabra rompiendo el silencio y construyendo otra narración que desarticulara la ficción de la fuga y que diera a conocer las características del crimen ${ }^{76}$. En este marco debe leerse la distribución de volantes que transcribían la declaración de los familiares y la intervención de "Alianza" en el "Festival por la libertad" donde buscó contraponer el relato de los heridos y sus rasgos desgarradores, con la información oficial.

Si la verdad de lo sucedido se conoció una semana después, las manifestaciones de protesta se concretaron desde el primer momento. En estas iniciativas pueden rastrearse las claves de lectura del acontecimiento: a) como hecho episódico de una violencia sistémica. Para la JUC, era una muestra de la violencia imperante "en todos los órdenes de la realidad". Los docentes y alumnos del "Juan XXIII" veían los asesinatos en el marco de una "guerra civil" que hundía sus raíces en una situación de "violencia legalizada"; b) como expresión de la violencia represiva de la dictadura. La JUC denunciaba la falta de respeto de la dignidad humana por parte de los detentadores del poder. Los estudiantes de la UNS leían Trelew como la cresta de una oleada represiva y el testimonio de los métodos con los que el régimen pretendía acallar la movilización popular; c) en particular, como símbolo del Gran Acuerdo Nacional. Para los universitarios, éste revelaba su faz represiva en vistas a obstaculizar el proceso revolucionario en marcha; d) como último manotazo de ahogado de un régimen en decadencia, incapaz de sostenerse por consenso. En la UNS sentenciaban que la violencia era para la dictadura el único medio para perpetuarse en el poder. $\mathrm{Y}$ en el Instituto salesiano consideraban que la mentira oficial era un síntoma de su "inexorable derrumbe"; e) como respuesta al avance incontenible de los sectores populares y como señal de un triunfo inminente. Según la asamblea universitaria, la dictadura pretendía

\footnotetext{
75 Pittaluga, Roberto, "La memoria según Trelew”, op. cit.

${ }^{76}$ Pittaluga, Roberto, "La memoria según Trelew", op. cit.
} 
"detener el ascenso de las luchas de la clase obrera y los trabajadores explotados", pero si debía apoyarse en la fuerza era porque se enfrentaba masivamente al pueblo.

Dada la cercanía de "Puerto Belgrano", no se trataba sólo de denunciar los asesinatos sino también de proteger la vida de los heridos. En esta dirección se orientaron las gestiones de los familiares, de los abogados y de los sectores católicos. Resulta pertinente pensar estas prácticas en una ciudad de dimensiones medias, lo que delimitaba un entretejido de redes sociales relativamente estrecho, y donde las esferas civil y militar estaban fuertemente imbricadas. Los vínculos personales facilitaron los contactos entre los actores, así como la elaboración de iniciativas comunes, mientras la presencia militar condicionó sus respuestas y actitudes.

\section{Referencias bibliográficas:}

Aguirre, Coral, Memorias del teatro combatiente: Teatro Alianza, Teatro para el Hombre y Teatro Laboratorio Bahía Blanca 1969-1989, Bahía Blanca, EDIUNS, 2015.

Bonavena, Pablo, "Notas sobre el movimiento estudiantil de Bahía Blanca (1966-1973)", en Bonavena, Pablo et. al., Apuntes sobre la formación del movimiento estudiantil argentino (19431973), Buenos Aires, Final Abierto, 2010, págs. 225-254.

Chama, Mauricio, "Movilización y politización: abogados de Buenos Aires entre 1968 y 1973”, en Perotin-Dumon, Anne, (dir.), Historizar el pasado vivo en América Latina, 2007, págs. 1-26, en línea en: http://www.historizarelpasadovivo.cl// consulta: 01/09/2015.

Dominella, Virginia, Catolicismo liberacionista y militancias contestatarias en Babia Blanca: sociabilidades y trayectorias en las ramas especializadas de Acción Católica durante la efervescencia social y política de los años '60 y '70, Tesis de Doctorado en Historia, Universidad Nacional de La Plata, La Plata, 2015, 500 págs., en línea en: http://www.memoria.fahce.unlp.edu.ar/tesis/te.1180/te.1180.pdf., consulta: 28/4/2017.

Dominella, Virginia, "Espacios de sociabilidad, redes sociales de la renovación católica y militancia contestataria en Bahía Blanca (Argentina), entre 1968 y 1975”, Revista Cultura y Religión, vol. IX, nro. 1, Universidad Arturo Prat del Estado de Chile, Iquique, enero-junio de 2015, págs. 102-128, en línea en:

www.revistaculturayreligion.cl/index.php/culturayreligion/article/download/593., consulta: $15 / 01 / 2017$.

Eidelman, Ariel, "El PRT-ERP y la lucha por la libertad de los presos políticos, 1971-1973", Sociobistórica, 25, La Plata, primer semestre de 2009, págs. 13-39.

Giménez, Julia, Ciudad de "Perros". Historias de militancia y recorridos del PRT-ERP por la ciudad de Babía Blanca., Tesis de Licenciatura en Historia, Universidad Nacional del Sur, Bahía Blanca, 2008.

Montero, Lorena, "Memorias del golpe en La Nueva Provincia", en Cernadas, Mabel y Marcilese, José (ed.), Cuestiones políticas, socio-culturales y económicas del Sudoeste Bonaerense, Archivo de la memoria, UNS, Bahía Blanca, 2006.

Orbe, Patricia, La politica y lo politico en torno a la comunidad universitaria babiense (1955-1976). Estudio de grupos, ideologias y producción de discursos, Tesis de Doctorado en Historia, Universidad Nacional del Sur, Bahía Blanca, 2007.

Pittaluga, Roberto, "La memoria según Trelew", Sociobistórica, 19/20, La Plata, 2006, págs. 81-111.

Romero Wimer, Fernando y Becher, Pablo, "Los estudiantes y las luchas de calles en Bahía Blanca durante 1972", Conflicto Social, año 4, $\mathrm{n}^{\circ}$ 5, Buenos Aires, 2011, en línea en: http://webiigg.sociales.uba.ar/conflictosocial/revista/05/12_wimwer-becher.pdf., consulta: 14/07/15. 
Vidal, Ana, Experiencias del teatro militante en Babia Blanca, 1972-1978, Tesis de doctorado en Historia, Universidad Nacional del Sur, Bahía Blanca, 2016.

Zapata, Belén, Páginas Manchadas. Conflictividad laboral entre los gráficos y La Nueva Provincia en vísperas de la dictadura de 1976, Tesis de Licenciatura en Historia, Universidad Nacional del Sur, Bahía Blanca, 2008.

Zapata, Belén, Andamios de experiencias: Conflictividad obrera, vigilancia y represión en Argentina. Babia Blanca, 1966-1976, Tesis de Doctorado en Historia, Universidad Nacional de La Plata, La Plata, 2014. 